\title{
Spiders actively choose and feed on nutritious non-prey food resources
}

\author{
Jacinto Benhadi-Marín ${ }^{\mathrm{a}, \mathrm{b}, *}$, José Alberto Pereira ${ }^{\mathrm{a}}$, José Paulo Sousa ${ }^{\mathrm{b}}$, Sónia A.P. Santos ${ }^{\mathrm{c}, \mathrm{d}}$

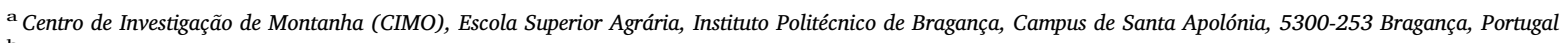 \\ ${ }^{\mathrm{b}}$ Centre for Functional Ecology, Department of Life Sciences, University of Coimbra, Calçada Martim de Freitas, 3000-456 Coimbra, Portugal \\ ' CIQuiBio, Barreiro School of Technology, Polytechnic Institute of Setúbal, Rua Américo da Silva Marinho, 2839-001 Lavradio, Portugal \\ d LEAF, Instituto Superior de Agronomia, Tapada da Ajuda, 1349-017 Lisboa, Portugal
}

\section{A R T I C L E I N F O}

\section{Keywords:}

Guilds

Sugars

Protein

Honeydew

Predators

\begin{abstract}
A B S T R A C T
Spiders are generalist predators adapted to consume a wide range of prey although their ability to exploit nonprey foods such as pollen, nectar, and honeydew has been referred but less studied. In this work, we investigated the effect of different non-prey food items (Glucose at $0.5 \mathrm{M}$; aphid honeydew; black scale honeydew; a mixture of glucose $0.5 \mathrm{M}$, phenylalanine $0.1 \mathrm{mM}$, proline $0.1 \mathrm{mM}$, and tryptophan $0.1 \mathrm{mM}$; honey at $10 \%$, and pollen at $10 \%$ ) on the survival of immature spiders of two functional groups represented by Haplodrassus rufipes (ground hunters) and Synema globosum (ambushers), and their feeding choices, in laboratory experiments. The overall survival of both species fed on non-prey foods significantly increased compared to individuals fed on water. The black-scale honeydew was the best food for $H$. rufipes increasing longevity up to 117 days. The highest survival reached by $S$. globosum was observed when fed on a mixture of glucose $0.5 \mathrm{M}$ and three amino acids. When different non-prey food items were offered together, the exploring rate was significantly higher for $H$. rufipes than for S. globosum. H. rufipes chose to feed on honey whereas $S$. globosum chose the mixture treatment. The most chosen food items corresponded with those that provided the highest longevities in both species. Our results suggest that spiders could search, recognize and actively select the most beneficial non-prey food. Habitat management practices such as maintaining weed strips in the crop may provide these valuable supplementary food resources within agroecosystems contributing for biological pest control.
\end{abstract}

\section{Introduction}

Natural enemies feeding on different supplementary food resources such as nectar, sugar, and pollen experience higher levels of fitness and can enhance biological pest control (van Rijn et al., 2002). Generally, the advantages of a prey-based diet for entomophagous predators surpass those of a diet based on non-prey foods in terms of nutrient contents (Lundgren, 2009). However, both quantity and quality of nonprey food resources available for natural enemies can influence different life-history parameters such as survival, reproduction and number of offsprings, consequently affecting their efficiency in pest suppression (Villa et al., 2016).

Among predators, the role of spiders within agricultural landscapes is well documented and several studies showed that spiders are important natural enemies of pests (Benhadi-Marín et al., 2016; Picchi et al., 2017). Spiders have been considered strictly carnivores, however, evidences related with their capacity to feed on floral resources such as nectar and pollen have been regularly reported (Vogelei and Greissl,
1989; Sanders, 2012).

Glucophagy in spiders can improve longevity and fitness and affect molting (Taylor and Pfannenstiel, 2009). Wu et al. (2011) observed, in laboratory experiments, that the crab spider Ebrechtella tricuspidata (Fabricius) (Thomisidae) significantly spent more time feeding on honey solution $(20 \%)$ than on water. Moreover, spiders fed on the honey solution significantly showed higher survival rates, shorter developmental time and pre-oviposition period, and laid more eggs than those spiders fed on water only. Different studies proved that feeding on pollen also increased the fitness of the spiders especially during the first instars (Vogelei and Greissl, 1989) and observations of spiders feeding on pollen have been reported for cursorial spider families such as Thomisidae, Salticidae, Clubionidae and Eurichuridae, and webbuilders such as Araneidae, Linyphiidae and Theridiidae (Nyffeler et al., 2016). Also, it has been suggested that pollen availability could lead to the association between spiders and different species of plants (Ruhren and Handel, 1999).

Another important alternative food resource and one of the most

\footnotetext{
* Corresponding author at: Centro de Investigação de Montanha (CIMO), Escola Superior Agrária, Instituto Politécnico de Bragança, Campus de Santa Apolónia, 5300-253 Bragança, Portugal.

E-mail address: jbenma@hotmail.com (J. Benhadi-Marín).
} 
abundant in infested crops as well as in spontaneous non-crop plants is the honeydew excreted by hemipteran insects (Vollhardt et al., 2010; Pfannenstiel and Patt, 2012). Pfannenstiel (2015) found, in laboratory experiments, that the whitefly (Hemiptera: Aleyrodidae) honeydew significantly extended the survival of spiders belonging to different functional groups such as Apollophanes punctipes (O.P. Cambridge) (Philodromidae), Cesonia bilineata (Hentz) (Gnaphosidae), Dictyna sp. (Dictynidae), Hibana futilis (Banks) (Anyphaenidae), and Thiodina sylvana (Hentz) (Salticidae). Several observations were also made in the field, for example, different species of Myrmarachne (Salticidae) have been seen feeding on honeydew while tending scale coccid insects (Nyffeler et al., 2016).

In terms of behavior, spiders show different patterns to exploit alternative non-prey foods. Misumenoides formosipes (Walckenaer) (Thomisidae) actively squeeze nectaries in flowers with the fangs (Pollard et al., 1995). Orb-weaver spiders such as Araneus diadematus Clerck (Araneidae) can ingest their orbicular web covered with pollen grains taking advantage of this type of food (Ludy and Lang, 2006). Jumping spiders also exploit extrafloral nectaries since they are easily accessed (Ruhren and Handel, 1999) and ambusher spiders such as Thomisus onustus Walckenaer (Thomisidae) use flowers to hunt pollinators, and in laboratory studies, immatures of this species survived for 40 days when fed on pollen only (Vogelei and Greissl, 1989).

Both visual cues and odor are related with spider feeding behavior. Heiling et al. (2004) demonstrated that odor seems to be the floral signal that bees use to identify high-quality flowers and that crab spiders exploit to encounter honeybees; and testing at the same time the predator and the prey, both preferred the flowers that emitted olfactory signals. Patt and Pfannenstiel (2008) pointed out that nectarivorous spiders may have mechanisms for detecting, recognizing and locating nectar sources.

Although vegetarianism and glucofagy in spiders has aroused interest, the way in which non-prey food such as nectar, pollen and honeydews affect the fitness of different guilds of spiders as well as the preference for some non-prey foods is still largely unknown. The objective of this work was to assess the effect of different non-prey foods on the survival and food selection behavior of two species of spiders, Haplodrassus rufipes (Lucas) (Gnaphosidae) and Synema globosum (Fabricius) (Thomisidae), encompassing two functional groups, the ground hunters and ambushers respectively. Our working hypotheses were that (1) non-prey foods will significantly increase the survival of immature spiders and (2) the spiders will preferentially choose some food items in multiple-choice experiments.

Haplodrassus rufipes and $S$. globosum are two widespread spider species in the Iberian Peninsula (Morano et al., 2014), the former has a Mediterranean distribution and the latter has a Palearctic distribution (Nentwig et al., 2018). Both species are generalist predators and in this study they were selected as representatives of two functional groups according to their hunting strategies. Haplodrassus rufipes is a nocturnal ground runner spider that builds its nests under stones and uses them as shelters during the day (Benhadi-Marín, J., personal observation). Synema globosum is an ambusher species that hunts insects on flowers during the day and nests under the flower or by joining two nearby flowers (Ajuria and Reader, 2014).

\section{Material and methods}

\subsection{Spider origin and rearing}

Subadults of both sexes of $H$. rufipes and $S$. globosum were hand collected in Valbom-dos-Figos $\left(41^{\circ} 32^{\prime} 58^{\prime \prime} \mathrm{N}\right)$ and Cedães $\left(41^{\circ} 29^{\prime} 17^{\prime \prime} \mathrm{N}\right)$, two villages located in the vicinities of the municipality of Mirandela (northeast of Portugal) in the beginning of May 2015 and 2016. Specimens of $H$. rufipes were searched under soil stones in an olive grove in Valbom-dos-Figos and specimens of $S$. globosum were captured by inspecting flowers of Cistus ladanifer L. in a semi-natural shrubland area in Cedães.

The spiders were transported into the laboratory in perforated plastic tubes (volume $-15 \mathrm{~mL}$ ), transferred individually into plastic Petri dishes $(5.2 \mathrm{~cm}$ in diameter and $1.2 \mathrm{~cm}$ height) and placed in a climate chamber at $21^{\circ} \mathrm{C}\left( \pm 1{ }^{\circ} \mathrm{C}\right), 70 \%( \pm 5 \%)$ of relative humidity and a photoperiod of 16:8 (L:D) h. Every week, half of a $2 \mathrm{~cm}$ sphere of sodium acrylate hydrogel was placed on the bottom of each Petri dish to provide water.

Haplodrassus rufipes was fed on the first nymphal stages of the house cricket, Acheta domesticus (L.) (Orthoptera: Gryllidae). Acheta domesticus specimens were initially purchased in a pet shop and maintained in the laboratory. The initial cricket population ( $\approx 100$ individuals) was placed into a plastic box $(35 \mathrm{~cm} \times 25 \mathrm{~cm}$ on the base and $30 \mathrm{~cm}$ in height) covered with a multiperforated cap. A layer of $2 \mathrm{~cm}$ in height of cat litter was provided as substrate. A plastic Petri dish $(5.2 \mathrm{~cm}$ in diameter and $1.2 \mathrm{~cm}$ height) was placed on each box corner and filled with meat-based dried biscuit-like minced cat food as nourishment. Water was provided with 10 spheres of sodium acrylate hydrogel $(2 \mathrm{~cm}$ in diameter) placed randomly on the litter surface. Eight egg cartons were aligned in the enclosure to provide shelter. Six small plastic boxes $(6 \mathrm{~cm} \times 6 \mathrm{~cm}$ on the base and $3.5 \mathrm{~cm}$ in height) covered with metal mesh and filled with moistened cat litter were placed randomly on the substrate as egg laying boxes. After a week, the laying boxes were removed from the culture and placed on a tray previously filled with a substrate consisting of a mixture of cat litter and minced cat food $(1 \mathrm{~cm}$ in height). The tray carrying the laying boxes was maintained in a $30{ }^{\circ} \mathrm{C}$ climate chamber until egg hatching. After hatching, the small juveniles spontaneously jump from the laying boxes and fall into the tray, becoming ready to be used.

Synema globosum was fed on adults of the Mediterranean fruit fly, Ceratitis capitata (Wiedemann) (Diptera: Tephritidae) that were collected from the stock colony maintained at the School of Agriculture (ESA), Bragança since September 2012, as described before by Dinis et al. (2016). Both prey species were provided ad libitum to spiders during the rearing stage.

When the spiders reached the adult stage, 20 couples of both species were placed individually in Petri dishes $(9 \mathrm{~cm}$ in diameter and $2 \mathrm{~cm}$ height) and observed until mating. After that, each female was reallocated in its Petri dish and males were released in the field. Cocoons built by females were sequentially taken from the dishes, placed into plastic Petri dishes $(5.2 \mathrm{~cm}$ in diameter and $1.2 \mathrm{~cm}$ height) and maintained with a moistened filter paper strip until spiderlings hatched.

\subsection{Non-prey food}

The non-prey food used in the experiments were: (1) three different saccharides, i.e., (a) glucose (D- $(+)$-glucose $>99 \%$ ), (b) sucrose (D$(+)$-sucrose $>99 \%)$, both purchased from Fisher Scientific, Loughborough, UK and (c) fructose (D- $(-)$-fructose $>99 \%$ ) purchased from PanReac AppliChem, Darmstadt, Germany, (2) three different amino acids, i.e., (a) phenylalanine (purchased from PanReac AppliChem, Darmstadt, Germany), (b) proline and (c) tryptophan (both purchased from Acros Organics ${ }^{\mathrm{TM}}$, New Jersey, USA), (3) commercial multifloral organic honey (as a mimic for nectar) obtained from Agrupamento de Produtores de Mel do Parque, Lda. (Bragança, Portugal), (4) bee-collected pollen obtained from an organic beekeeper (Manuel C. Martins Chêta, Pereiras, Portugal), (5) yeast extract (purchased from Biolab ${ }^{\circledR}$ Zrt., Budapest, Hungary), (6) black scale Saissetia oleae (Olivier) honeydew and (7) aphid Aphis craccae L. honeydew. The black scale honeydew was collected from infested leaves of small olive trees grown in a climatic chamber at $24^{\circ} \mathrm{C}\left( \pm 1{ }^{\circ} \mathrm{C}\right), 70 \%( \pm 5 \%)$ of relative humidity and a photoperiod of $16: 8 \mathrm{~h}$ (L:D) and the aphid honeydew was collected from infested plants of Vicia villosa Roth collected in the field and maintained in the same climatic chamber. In both cases, several Parafilm strips were placed under the infested parts of the plants and used in the experiments when they were mostly covered by 
small drops of honeydew after $24 \mathrm{~h}$ on average.

\subsection{Experimental design}

\subsubsection{Longevity experiments}

A preliminary longevity experiment was performed in order to select which of the saccharides will be used as a positive control in the following experiments. Thus, recently hatched spiderlings of $H$. rufipes $(<24 \mathrm{~h})$ were transferred individually into each well of a 24-well plate. Each specimen was provided with a filter paper strip $(1 \mathrm{~cm} \times 1 \mathrm{~cm})$ which was embedded in a sugar solution and placed at the bottom of the well. Sugar solutions of glucose, sucrose and fructose at concentrations of $0.25 \mathrm{M}, 0.5 \mathrm{M}$ and $1 \mathrm{M}$ were tested. Water was used as negative control. Each well was closed with a cotton ball wrapped in Parafilm to prevent the spider from escaping. Since glucose at $0.5 \mathrm{M}$ gave the higher mean longevity (shown in Results section), this solution was selected as the positive control.

For the following longevity experiments, the spiderlings of each spider species were kept, in the 24-well plates, with one of the non-prey foods, i.e., (1) water as negative control, (2) solution of glucose at $0.5 \mathrm{M}$ as positive control, (3) solution of honey at $10 \% \mathrm{v} / \mathrm{v}$, (4) solution of pollen at $10 \% \mathrm{w} / \mathrm{v},(5)$ a mixture of glucose $0.5 \mathrm{M}$, phenylalanine $0.1 \mathrm{mM}$, proline $0.1 \mathrm{mM}$ and tryptophan $0.1 \mathrm{mM}$ (hereafter mix), (6) the black scale honeydew, and (7) aphid honeydew. Each specimen was provided with a filter paper strip $(1 \mathrm{~cm} \times 1 \mathrm{~cm})$ embedded in the respective solution or with a Parafilm strip $(1 \mathrm{~cm} \times 1 \mathrm{~cm})$ covered with drops of honeydew and a filter paper strip embedded in water under the Parafilm strip, that were placed at the bottom of the well.

Each non-prey food was changed twice a week to prevent fungal growth. Experiments were maintained in a climate chamber at $21{ }^{\circ} \mathrm{C}$ $\left( \pm 1{ }^{\circ} \mathrm{C}\right), 70 \%$ ( $\pm 5 \%$ ) of relative humidity and a photoperiod of $16: 8 \mathrm{~h}$ (L:D) and spiderling survival was checked and registered on a daily basis. Between 47 and 55 individuals were used in each treatment.

\subsubsection{Food choices and behavior during multiple-choice experiments}

Recently hatched spiderlings of each species $(<24 \mathrm{~h})$ were tested in order to check if they actively searched and/or chose a specific nonprey food. In this experiment, glass Petri dishes $(5.2 \mathrm{~cm}$ in diameter and $1.2 \mathrm{~cm}$ height) were used and the vertices of a hexagon $(1.5 \mathrm{~cm}$ radius) were drawn on the bottom surface. One drop of moistened activated charcoal powder $(0.02 \mathrm{~g} / \mathrm{drop})$ (AppliChem ${ }^{\circledR}$ PanReac, Darmstadt, Germany) was placed, with a syringe, on each vertex of the hexagon. After the activated charcoal dried, a drop of each non-prey food solution was deposited onto the surface using a syringe and offered to the spiderling.

Six non-prey food were tested simultaneously in each Petri dish (multiple choice experiment): (1) water as negative control (2) glucose at $0.5 \mathrm{M}$ as positive control (3) honey at $10 \% \mathrm{v} / \mathrm{v},(4)$ pollen at $10 \% \mathrm{w} /$ $\mathrm{v}$, (5) mixture of glucose $0.5 \mathrm{M}$, phenylalanine $0.1 \mathrm{mM}$, proline $0.1 \mathrm{mM}$ and tryptophan $0.1 \mathrm{mM}$ and (6) yeast extract at $10 \% \mathrm{w} / \mathrm{v}$.

The spiderlings were maintained at $4{ }^{\circ} \mathrm{C}$ for $10 \mathrm{~min}$ to reduce activity. Then, after one minute at room temperature $\left(23^{\circ} \mathrm{C}\right)$, a spiderling was placed individually using a paintbrush in the center of the Petri dish and all the movements were recorded for $30 \mathrm{~min}$ using a Computar $^{\circledR}$ lens (H2Z0414C-MP, $\mathrm{f}=4-8 \mathrm{~mm}, \mathrm{~F} 1.4,1 / 2$ ", CCTV lens) mounted on a Basler ${ }^{\oplus}$ GigE HD Camera (acA1300-60gc with e2v EV76C560 CMOS sensor) (Noldus, 1991). The Noldus Observer XT 11.5 software (Noldus Observer XT, 2013a) was used to encode the ethogram and to gather the data. The ethogram was encoded in two behaviors, "inactive" and "active", the latter included seven modifiers: "honey", "pollen", "glucose", "mix", "yeast", "water" and "exploring". A resource was considered selected when a spiderling climbed onto a non-prey food drop and touched it with at least the prosoma.

The Media Recorder 2.5 software (Noldus Media Recorder, 2013b) was used and the Petri dishes illuminated with fluorescent direct light. Fifty-four individuals of each species were tested and were video- recorded in nine blocks of six Petri dishes per block.

\subsection{Data analysis}

\subsubsection{Longevity experiments}

The mean, median, interquartile range and standard error of the longevity were calculated for each non-prey food. Firstly, the longevity was modeled using a Poisson GLM in order to test for interactions between the type of sugar and the different concentrations. Since the variance was larger than the mean, the standard errors were corrected using a quasi-GLM model given by:

$$
\begin{aligned}
Y_{i} P^{\sim}\left(\mu_{i}\right) & ; E\left(Y_{i}\right)=\mu_{i} \text { and } \operatorname{var}\left(Y_{i}\right)=\varphi \times \mu_{i} \\
\log \left(\mu_{i}\right)= & \alpha+\beta_{1} \times \text { Sugar }_{i 1}+\beta_{2} \times \text { Concentration }_{i 2}+\beta_{3} \times \text { Sugar }_{i 3} \\
& : \text { Concentration }_{i 3}
\end{aligned}
$$

where $\varphi$ is the dispersion parameter and $\beta_{3} \times$ Sugar $_{i 3}$ :Concentration ${ }_{i 3}$ the interaction term. Models were validated by checking lack of fit and patterns in the deviance residuals (Zuur et al., 2009). Since the interaction term of Eq. (1) was significant, the treatment overall effect was assessed through survival curves using log-rank tests for all sugars and concentrations. Then, the differences between non-prey foods were evaluated by a full sequential pairwise comparison analysis. Finally, differences between spider species were assessed using the Wilcoxon signed-rank test. The significance level was established at $\mathrm{p}=0.01$ in all cases.

\subsubsection{Food choices and behavior during multiple-choice experiments}

The rate per minute (hereafter RPM) of the analyzed observation duration (i.e. the mean number of occurrences of a behavior over the total of the analyzed duration) was calculated for each modifier and Petri dish as:

$\mathrm{RPM}_{\mathrm{i}}=\left(\right.$ Total number of occurrences $\left.\mathrm{i}_{\mathrm{i}} \times 60\right) /$ Analyzed duration $_{\mathrm{i}}(\mathrm{s})$

The exploring rate within the Petri dish was firstly compared between species in order to assess the activity rate of each species with the Welch's $t$-test due to unequal variances (D). Then, the RPM of the modifiers honey, pollen, glucose, mix, yeast, and water were compared by developing general linear mixed models (GLMMs) according to Zuur et al. (2009) followed by a post hoc multiple comparisons analysis $(\alpha=0.05)$. Block was included as a random factor $\left(Z_{i} \times b_{i}\right)$ and water was used as intercept. In the case of $H$. rufipes, a second term for the time spent in each resource (Duration) was included in the model to correct the exploring rate effect. Models were validated checking for nonlinear patterns in the residuals. The final models are given by:

$\mathrm{b}_{\mathrm{i}} \sim N(0, \mathrm{D}) \varepsilon_{i} \sim N\left(0, \Sigma_{i}\right)$

S. globosum: $R P M_{i} \sim \alpha+\beta \times$ non_preyfoods $s_{i}+Z_{i} \times b_{i}+\varepsilon_{i}$

H. rufipes: $R P M_{i} \sim \alpha+\beta_{1} \times$ non_preyfoods $s_{i 1}+\beta_{2} \times$ Duration $_{i 2}+Z_{i} \times b_{i}$

$+\varepsilon_{i}$

Finally, for both species and experiment the mean of each treatment was centered around zero, scaled by dividing the centered values by their standard deviations and plotted together to check for patterns between the most selected non-prey foods and the treatments that provided the highest longevity.

All statistical analyses and modeling were performed in R (R Core Team, 2018). The functions used outside the $\{$ base $\}$ and \{stats\} packages were: Anova $\{c a r\}$, effect $\{$ effects $\}$, glht $\{$ multcomp $\}$, lmer \{lme4\}, lsmeans $\{$ lmerTest $\}, \operatorname{mcp}\{$ multcomp $\}$, multcompLetters $\{$ multcompView\}, plotCI\{plotrix\}, std.error\{plotrix\}, survdiff \{survival\} and survfit $\{$ survival\}. 
Table 1

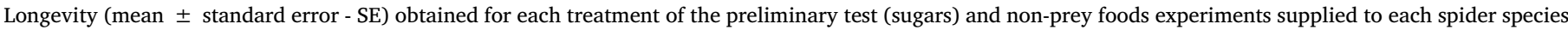

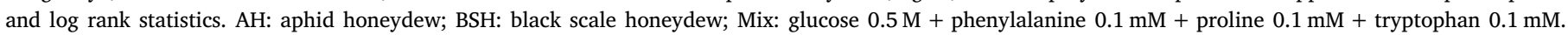
Different letters for longevity means significant differences between treatments within each assay (pairwise comparisons) ( $\mathrm{p}<0.01$ ).

\begin{tabular}{|c|c|c|c|c|c|}
\hline Assay & Treatment & Longevity (mean $\pm \mathrm{SE}$ ) & Observed & Expected & $(O-E)^{\wedge} 2 / E$ \\
\hline \multirow[t]{10}{*}{ Sugars (H. rufipes) } & Water & $25.47 \pm 1.23 \mathrm{a}$ & 53 & 13.89 & 110.11 \\
\hline & Fructose $0.25 \mathrm{M}$ & $42.73 \pm 1.81 \mathrm{bc}$ & 55 & 49.24 & 0.67 \\
\hline & Fructose $0.5 \mathrm{M}$ & $34.77 \pm 2.21 \mathrm{~b}$ & 47 & 28.29 & 12.38 \\
\hline & Fructose $1 \mathrm{M}$ & $45.20 \pm 3.03 \mathrm{~cd}$ & 54 & 69.09 & 3.30 \\
\hline & Glucose $0.25 \mathrm{M}$ & $44.65 \pm 1.42 \mathrm{bc}$ & 54 & 50.44 & 0.25 \\
\hline & Glucose $0.5 \mathrm{M}$ & $51.02 \pm 2.41 \mathrm{~d}$ & 55 & 79.98 & 7.80 \\
\hline & Glucose $1 \mathrm{M}$ & $45.65 \pm 2.82 \mathrm{~cd}$ & 51 & 62.27 & 2.04 \\
\hline & Sucrose $0.25 \mathrm{M}$ & $42.19 \pm 1.62 \mathrm{bc}$ & 54 & 46.39 & 1.25 \\
\hline & Sucrose $0.5 \mathrm{M}$ & $45.48 \pm 3.01 \mathrm{~cd}$ & 50 & 63.43 & 2.84 \\
\hline & Sucrose $1 \mathrm{M}$ & $44.98 \pm 3.06 \mathrm{~cd}$ & 48 & 57.97 & 1.72 \\
\hline \multirow[t]{7}{*}{ Non-prey foods (H. rufipes) } & $\mathrm{AH}$ & $29.74 \pm 0.99 a$ & 55 & 18.27 & 73.81 \\
\hline & $\mathrm{BSH}$ & $72.20 \pm 2.62 \mathrm{~d}$ & 51 & 108.32 & 30.33 \\
\hline & Glucose $0.5 \mathrm{M}$ & $51.02 \pm 2.41 c$ & 55 & 60.93 & 0.58 \\
\hline & Honey $10 \%$ & $59.22 \pm 2.42 c$ & 51 & 74.30 & 7.31 \\
\hline & Mix & $51.54 \pm 2.86 c$ & 55 & 64.61 & 1.43 \\
\hline & Pollen $10 \%$ & $37.92 \pm 2.25 b$ & 53 & 33.74 & 10.99 \\
\hline & Water & $25.47 \pm 1.23 \mathrm{a}$ & 53 & 12.82 & 125.93 \\
\hline \multirow[t]{7}{*}{ Non-prey foods (S. globosum) } & $\mathrm{AH}$ & $32.87 \pm 2.35 \mathrm{e}$ & 55 & 70.40 & 3.37 \\
\hline & $\mathrm{BSH}$ & $26.67 \pm 2.28 b c$ & 55 & 46.80 & 1.44 \\
\hline & Glucose $0.5 \mathrm{M}$ & $28.11 \pm 0.68 \mathrm{cde}$ & 55 & 55.50 & 0.00 \\
\hline & Honey $10 \%$ & $20.13 \pm 1.55 b$ & 55 & 31.00 & 18.50 \\
\hline & Mix & $41.61 \pm 2.55 f$ & 55 & 110.60 & 28.00 \\
\hline & Pollen $10 \%$ & $29.38 \pm 1.31 \mathrm{~d}$ & 55 & 55.60 & 0.01 \\
\hline & Water & $15.00 \pm 0.53 \mathrm{a}$ & 55 & 15.10 & 105.00 \\
\hline
\end{tabular}

\section{Results}

\subsection{Longevity experiments}

In the preliminary experiment, the interaction between the type and the concentration of the sugar significantly affected the longevity of $H$. rufipes $\left(\chi^{2}=99.345, \mathrm{df}=4, \mathrm{P}<0.01\right)$. The overall effect was also statistically significant $\left(\chi^{2}=159.70, \mathrm{df}=9, \mathrm{P}<0.01\right)$ and all sugars at any concentration significantly increased the survival of spiders (Table 1) (Fig. 1A). Among sugars and concentrations, glucose $0.5 \mathrm{M}$ was the combination that provided the highest mean longevity (Table 1), hence it was included as a positive control in the following experiments.

The overall survival of spiderlings of both species fed on non-prey foods significantly increased (H. rufipes: $\chi^{2}=309.50, \mathrm{df}=6, \mathrm{P}<0.01$ and $S$. globosum: $\left.\chi^{2}=196.00, \mathrm{df}=6, \mathrm{P}<0.01\right)$. In all cases, water caused the lowest values of longevity, however, it was not significantly different from the survival of $H$. rufipes fed on aphid honeydew (Table 1). For this species, four groups of non-prey foods differed significantly in terms of curve fitting and represented an increasing survival gradient. The first group included the spiderlings fed on water and aphid honeydew, the second one those fed on pollen, the third group those fed on glucose, honey and the mixture of glucose $0.5 \mathrm{M}$ and three amino acids, and the last group those spiderlings fed on the black-scale honeydew (Table 1) (Fig. 1B). A spiderling of $H$. rufipes fed on the blackscale honeydew survived for 117 days thus being the highest longevity among the whole study (Fig. 1B).

For $S$. globosum, the mixture of glucose $0.5 \mathrm{M}$ and three amino acids was the non-prey food that gave the highest mean longevity followed by the aphid honeydew, whereas the highest number of days survived by a spiderling (67 days) corresponded to the mixture of glucose $0.5 \mathrm{M}$ and three amino acids treatment (Fig. 1C) (Table 1). In this species, four significantly different non-prey foods gave an increasing longevity, namely honey $<$ pollen $<$ aphid honeydew $<$ mix, with two intermediate treatments, black-scale honeydew, and glucose (Table 1) (Fig. 1C).

\subsection{Food choices and behavior during multiple-choice experiments}

Significant differences were found among the choices of non-prey food items offered to $H$. rufipes $(\mathrm{F}=22.65, \mathrm{df}=5, \mathrm{P}<0.01)$ and $S$. globosum $(\mathrm{F}=4.34, \mathrm{df}=5, \mathrm{P}<0.01$ ) when provided together. The exploring rate was significantly higher in $H$. rufipes than in $S$. globosum $(\mathrm{t}=6.71, \mathrm{df}=53, \mathrm{P}<0.01)$ (Fig. 2A).

The RPMs measured on spiderlings of $H$. rufipes feeding on drops of water, glucose, pollen and mixture of glucose $0.5 \mathrm{M}$ and three amino acids were significantly lower than for those feeding on the honey drop (Fig. 2B). In the case of S. globosum, the RPMs measured on the individuals feeding on water, glucose and honey drops were significantly lower than on those feeding on the mixture of glucose $0.5 \mathrm{M}$ and three amino acids drops (Fig. 2C). For both species, the yeast drop was the second most accessed non-prey food but it did not significantly differ from the others (Fig. 2B and C).

Regarding both the longevity and multiple food-choice experiments, the highest longevity was provided by the preferred non-prey food in each spider, these being honey for $H$. rufipes and the mixture of glucose $0.5 \mathrm{M}$ and three amino acids for S. globosum (Fig. 3).

\section{Discussion}

Our results confirmed that (1) different non-prey foods affected differently the lifespan of immature spiders when provided as the only food source and (2) the spiders select the non-prey food that benefited more the longevity according to its lifestyle.

The longevity of the ambusher $S$. globosum increased significantly when fed on glucose, pollen and nectar compared with individuals fed on water-only. These results agree with those obtained by Vogelei and Greissl (1989) who fed spiderlings of the ambusher species T. onustus in laboratory and found that pollen and artificial nectar (a sucrose solution $30 \% \mathrm{w} / \mathrm{v}$ ) significantly increased their mean lifespan when compared with starved spiderlings.

Suetsugu et al. (2014) reported that Clubiona spp. (Clubionidae), a foliage runner spider, actively removed pollen from flowers of the nectariferous orchid Neottianthe cucullata (L.). The pollen offered to $H$. 

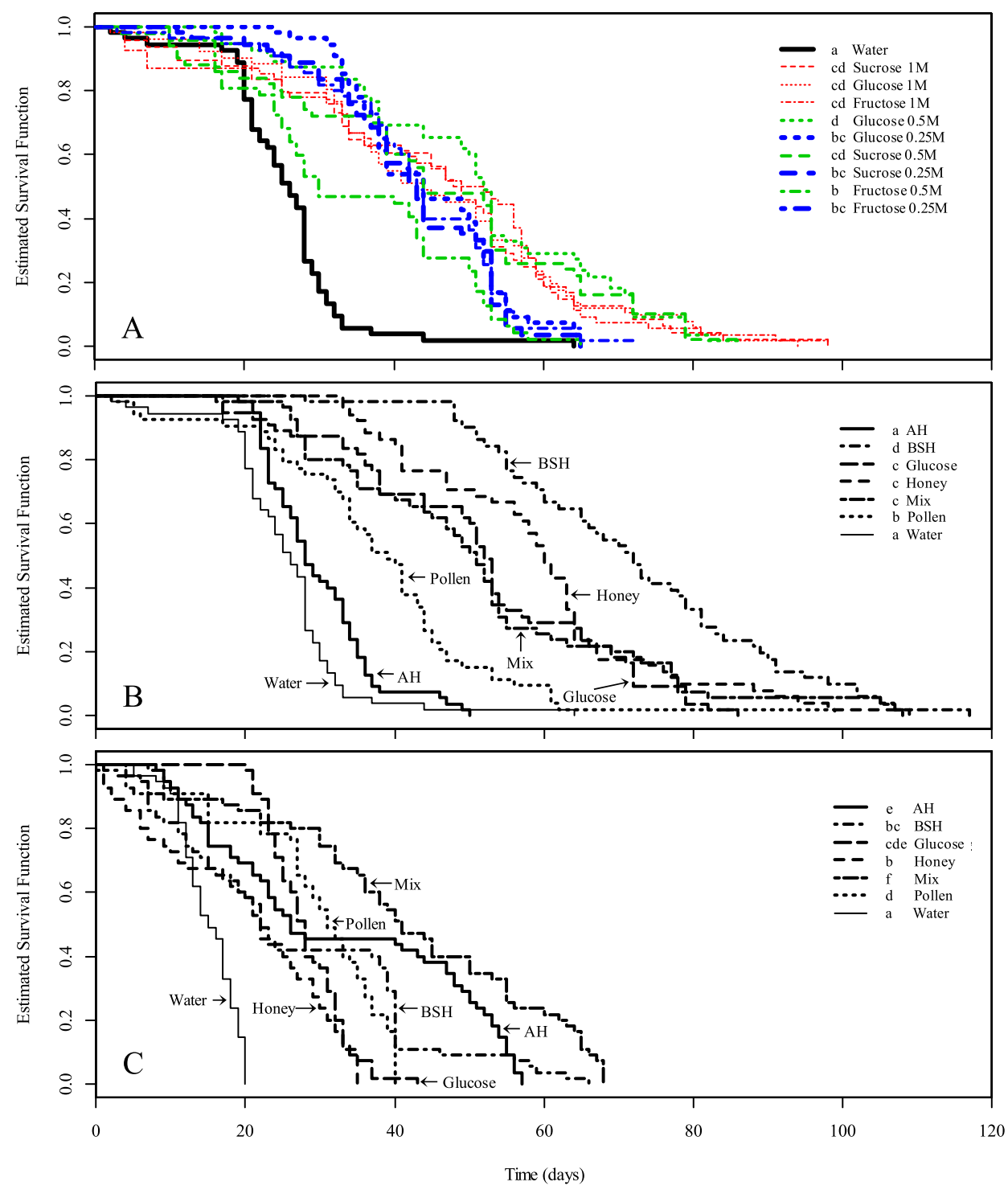

Fig. 1. Survival curves for each non-prey food tested. A: Sugars tested on Haplodrassus rufipes; B: Non-prey food tested on Haplodrassus rufipes; C: Non-prey food tested on Synema globosum. AH: aphid honeydew; BSH: black scale honeydew; Mix: glucose $0.5 \mathrm{M}+$ phenylalanine $0.1 \mathrm{mM}+$ proline $0.1 \mathrm{mM}+$ tryptophan $0.1 \mathrm{mM}$. Glucose at $0.5 \mathrm{M}$, honey and pollen at $10 \%$. Different letters in legends mean significant statistical differences between treatments $(\mathrm{p}<0.01)$.
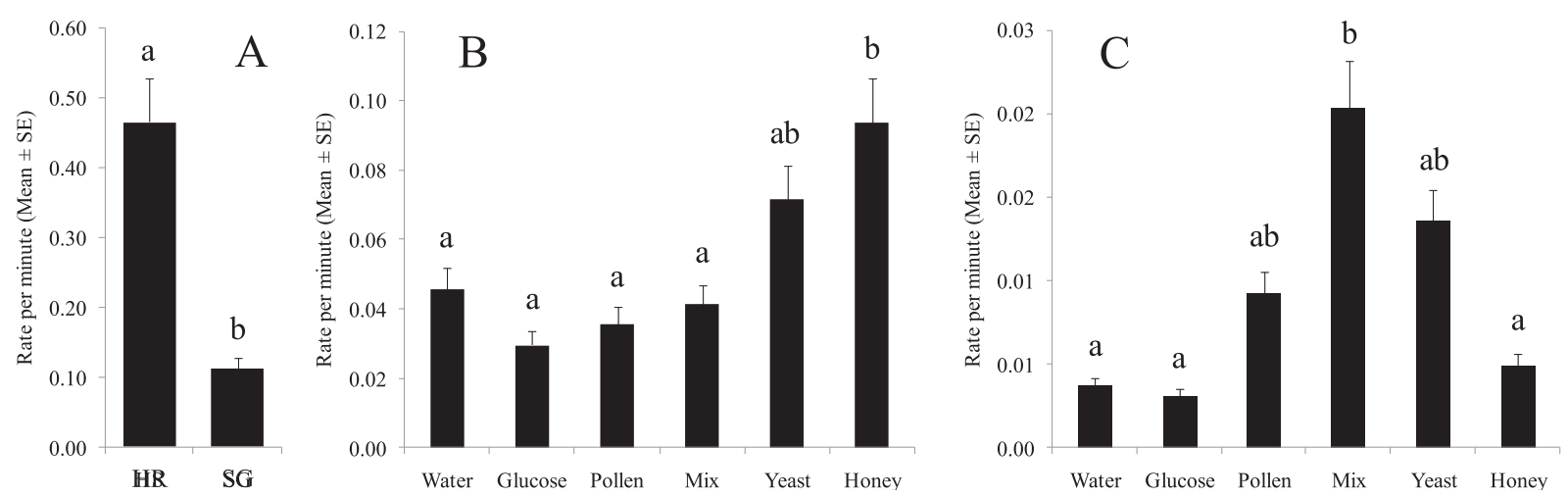

Fig. 2. A: Comparison between the mean exploring rate of each spider species. B: Selection rate of the different non-prey food offered to Haplodrassus rufipes. C: Selection rate of the different non-prey foods offered to Synema globosum. HR: H. rufipes; SG: S. globosum. Mix: glucose $0.5 \mathrm{M}+$ phenylalanine $0.1 \mathrm{mM}+$ proline $0.1 \mathrm{mM}+$ tryptophan $0.1 \mathrm{mM}$, glucose at $0.5 \mathrm{M}$. Honey, yeast and pollen at $10 \%$. Different letters over bars mean significant statistical differences (p < 0.05 ). 

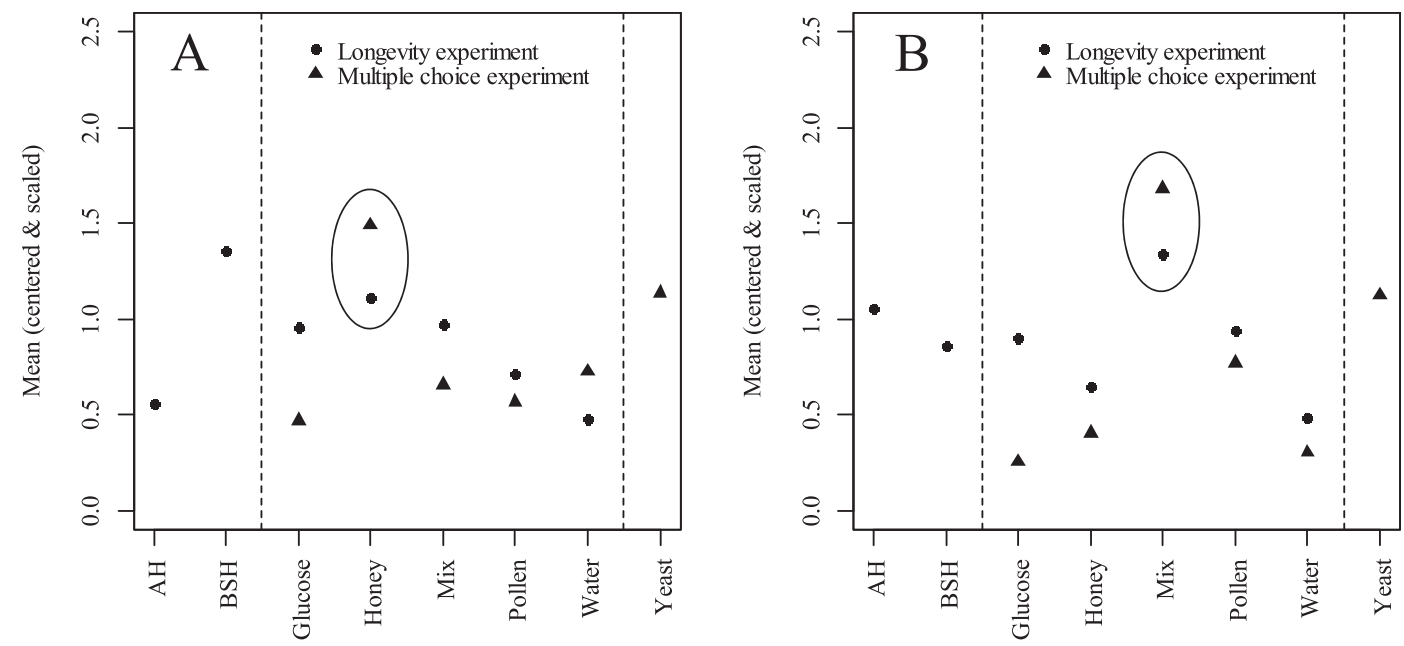

Fig. 3. Overlap of the longevity experiment and the multiple choice experiment for each spider species. Points and triangles correspond to the centered mean for each treatment and experiment at the same scale. The central area between the dashed lines corresponds to the intersection of the two experiments. The left area groups the treatments not used in the multiple choice experiments and the right area groups the treatments not used in the longevity experiment. A: Haplodrassus rufipes; B: Synema globosum; AH: aphid honeydew; BSH: black scale honeydew; Mix: glucose $0.5 \mathrm{M}+$ phenylalanine $0.1 \mathrm{mM}+$ proline $0.1 \mathrm{mM}+$ tryptophan $0.1 \mathrm{mM}$, glucose at $0.5 \mathrm{M}$, honey, pollen and yeast at $10 \%$. Among the treatments used in both experiments (central area), the ellipses encompass the treatment that provided the highest survival along the longevity experiment and the most selected treatment during the multiple choice experiment.

rufipes and $S$. globosum was embedded in water but the fact that active hunting spiders actually exploit this food source supports our results suggesting that pollen is effectively digested.

The spiderlings of $H$. rufipes tested in the present work survived significantly longer when fed on aphid honeydew and honey than those fed on water. In the case of cursorial spiders our results agree with Pfannenstiel and Patt (2012) who provided different non-prey foods to spiderlings of Cheiracanthium inclusum (Hentz) (Eutichuridae), in laboratory experiments, and reported an average increase of $870 \%$ on survival of spiders fed on extrafloral nectar of cotton plants, and of $626 \%$ on mealybug honeydew (Hemiptera: Pseudococcidae).

Honey (a mimic to nectar) was the second best treatment for $H$. rufipes and an intermediate one in the case of $S$. globosum in terms of spider survival. In both cases, it provided significantly better results than water, which seems to be a constant pattern among studies. Ruhren and Handel (1999) showed that foraging spiders spent 86\% more of their time on plants with nectar than without active extrafloral nectaries in a controlled-environment experiment, and Taylor and Pfannenstiel (2009) found, in laboratory, that the survivorship and the number of molts of $C$. inclusum spiderlings significantly increased when a supplement of nectar of Terminalia catappa L. was provided. Also, Chen et al. (2010) using the cold anthrone test confirmed that the ambusher E. tricuspidata and eight other spider families (Oxyopidae, Pisauridae, Salticidae, Lycosidae, Tetragnathidae, Araneidae, Nephilidae and Agelenidae) consumed nectar in the field.

Considering the two types of honeydew tested in this work, an opposite pattern was observed between spider species; the black-scale honeydew was the treatment that provided the highest longevity for $H$. rufipes whereas the aphid honeydew provided the second best result for S. globosum. This could be explained in terms of honeydew chemical composition. The major component of the black scale honeydew is trehalose $\left(193.3 \mathrm{mg} \mathrm{g}^{-1}\right)$ followed by sucrose $\left(25.0 \mathrm{mg} \mathrm{g}^{-1}\right)$, glucose and melibiose $\left(24.9 \mathrm{mg} \mathrm{g}^{-1}\right.$ ) (S. Santos, data not published). Trehalose is a naturally occurring 1-alpha sugar consisting of two molecules of glucose and known to be a stabilizer of proteins that helps to maintain the activity of enzymes in solution as well as in the freeze-dried state (Kaushik and Bhat, 2003). Also, beyond the energy obtained from sugar, trehalose provides effective protection against desiccation in invertebrates (Watanabe, 2006) which could explain the results achieved with the black-scale honeydew for both tested species. Moreover, $H$. rufipes is a species that spends the winter under stones, protected from cold, since it is considered less resistant to lower temperatures than spiders living unprotected in vegetation such as $S$. globosum (Nentwig, 1987). Accordingly, spiderlings of $H$. rufipes could benefit more from a diet rich in trehalose regarding the nutritional requirements necessary to overcome cold periods (e.g. daily temperature fluctuations and overwintering).

The honeydew of $A$. craccae fed on $V$. villosa also resulted in opposite patterns between $H$. rufipes and $S$. globosum and it was not significantly different from water for the former species. Despite differences between species, this result corroborates the previous idea since trehalose is a minor component $(<10 \%)$ occurring in the honeydew produce by Aphis fabae Scopoli fed on Vicia faba L (Fischer et al., 2005).

The three amino acids, phenylalanine, tryptophan and proline, provided together with glucose resulted in the best treatment in terms of survivorship for $S$. globosum and an intermediate one for $H$. rufipes. Proline varies up to $11 \%$ amino acids in silk and is thought to give elasticity (Creager et al., 2011). Silk is critical for many ecological functions of spiders and its production occurs during all developmental states representing a great energetic investment (Creager et al., 2011). Although the genetically encoded metabolic pathways remain unchanged by amino acid enrichment or deprivation, Zax et al. (2004) found that spiders of the species Argiope argentata (Fabricius) (Araneidae), Nephila clavipes (Linnaeus) (Araneidae), and Latrodectus hesperus (Chamberlin and Ivie) (Theridiidae) subjected to dietary deprivation incorporated less proline into the silk fiber than spiders provided with crickets. Moreover, silk profiles obtained from N. clavipes and $L$. hesperus fed on proline-rich diets showed clear proline peaks, while in natural conditions these peaks are difficult to discriminate above the baseline. This fact highlights the importance of this amino acid in the diet of spiders since the vast majority of spider silk is made up of alanine, glycine, proline, glutamic acid, and serine (Wilder, 2011).

Spiders use venoms to subdue prey and the combination of venom and extra-oral digestion allows spiders to exploit a wide spectrum of insect prey. Both secretions contain an array of active proteins and an overlap of some components has been reported and quantified (Walter et al., 2017). Phenylalanine is the second most important N-terminal amino acid residue of the cytolytic peptides of spider venom (KuhnNentwig et al., 2011) which highlights its importance for the spiders' extra-oral digestion. Since thomisids may bite several times to subdue the larger prey (e.g., bees and bumblebees) (Pollard, 1990; Foelix, 1996) and they can regulate the quantity of injected venom according 
to the prey size (Pollard, 1990), the amount of venom used during an attack may be high. In addition, it has been demonstrated that thomisids do not chew their prey, digestion taking place entirely extra-orally (Foelix, 1996) which should imply strong extra-oral fluids and venom (Foelix, 1996, 2011) that could make $S$. globosum preferentially choose a solution rich in phenylalanine such as the mix treatment.

Regarding the multiple choice experiment, it has been argued that spiders could determine the chemical properties of a substance merely by touching it with the chemosensitive hairs located in their tarsi (i.e. the seventh and last segment of the leg and sixth and last segment of the palp) (Foelix, 2011). This behavior called "taste-by-touch" and the chemical sensitivity of these sensilla has been proved using electrophysiological methods (Drewes and Bernard, 1976). Vallet et al. (1998) tested the sensitivity of chemoreceptors of Eratigena atrica (C.L. Koch) (Agelenidae) to 14 amino acids $(0.01 \mathrm{M}$ in $0.001 \mathrm{M} \mathrm{NaCl})$ and found that proline was the most stimulating one. Also, they found that chemoreceptors were functional in newly emerged individuals which can explain the selections did by spiderlings of $H$. rufipes and $S$. globosum when non-prey foods were offered together during the multiple choice experiment.

Mix was the most selected treatment by $S$. globosum whereas $H$. rufipes selected honey. $H$. rufipes showed a significantly higher activity rate and as an active hunter, honey could provide higher energy supply for this species. Although the total sugar content could be nearly the same in the honey treatment $(\approx 8.2 \% \mathrm{w} / \mathrm{w}$, reference value from Pasupuleti et al., 2017) and mix treatment $(\approx 8 \% \mathrm{w} / \mathrm{w})$, the diversity of sugars, proteins, vitamins and other compounds in honey together with a composition in amino acids dominated by proline (50-85\%) (Hermosín et al., 2003) could make the artificial nectar more attractive for $H$. rufipes.

On the other hand, S. globosum is a sit-and-wait predator with a presumably lower resting metabolic rate than the ground runner $H$. rufipes. Sit-and-wait spiders spend very little time in active locomotion and may be able to remain motionless by keeping constant hydrostatic pressure using a few small muscles instead of continually activating leg musculature (Wilder, 2011) thus reducing energy loss. In this sense, the non-prey food selection of the sit-and-wait species $S$. globosum could be driven by a lower sugar requirement and higher proline content of the mix treatment $(\approx 0.012 \% \mathrm{w} / \mathrm{w})$ when compared with the artificial nectar $(\approx 0.004 \% \mathrm{w} / \mathrm{w}$, reference value from Hermosín et al., 2003).

The yeast treatment was the second most selected by the two species. Spiders have been reported living in association with fruiting bodies of mushrooms and other fungi referring the latter as an excellent source of proteins (Lundgren, 2009) but fungus also contains lipids, minerals, carbohydrates, structure-fibers and the yeast may even act as a B-vitamin supplement (Kurtzmann, 1997). According to our results, we suggest that spiders could also exploit the ubiquitous biofilms present in nature as an alternative source of nutrients based on microorganisms.

Considering the non-prey foods provided in food choice experiments, both $H$. rufipes and $S$. globosum selected the food item that provided them the highest longevity during the non-choice experiment. These results agree with Patt and Pfannenstiel (2009) that demonstrated that the nocturnal cursorial $H$. futilis (Anyphaenidae) fed on non-prey foods not only to drink water but also to obtain nutrients.

Most biological control agents are omnivores since they usually feed on plant-derived foods and spiders are not an exception (Wäckers et al., 2008). Sap sucking hemipterans can be predated by spiders and the honeydew that they produce can also represent a supplementary source of energy. For example, the ambusher Philodromus albidus Kulczynski (Philodromidae) was observed feeding on a honeydew drop produced by the olive psyllid Euphyllura olivina Costa (Hemiptera) on the olive tree canopy (Benhadi-Marín, J., personal observation) and psyllids may encompass a great proportion of the canopy dwelling spiders diet (Barreales et al., data not published). Among other natural enemies, the lifespan of the parasitoid wasp Aphidius colemani (Dalman) fed on A. craccae honeydew was 2.5 times higher compared with longevity on water (Wäckers et al., 2008).

Our results suggest that different spider guilds react differently to non-prey foods and may process the nutrient composition in different ways. For example, honeydews can be less suitable and/or toxic for some consumers (Lundgren, 2009) and spiders could have different metabolic routes to deal with toxic compounds such as alkaloids or cardenolides. In fact, Bilde and Toft (2001) found a toxic effect on Erigone atra Blackwall (Araneae: Linyphiidae) when fed on Sitobion avenae Fabricius (Hemiptera: Aphididae) adults in laboratory. Thus, food selection during multiple-choice experiments could be driven by avoidance (due to toxic or inhibitory components) rather than by preference; however, the effect of this kind of substances in spiders remains unknown (Nyffeler et al., 2016). Further research on the chemical composition of non-prey foods involved in spider diets is mandatory as well as on the physiological mechanisms involved in the detection and selection of such alternative food sources.

Our results demonstrate that different functional groups of spiders actively search and consume the most beneficial non-prey food among those offered and provide strong evidence for the relevance of non-prey foods on diet. Spontaneous plants (flowers) and honeydew may provide important nutrients to immature spiders; however, each non-prey food alone is probably not enough to fulfill the nutritional requirements of an individual. Moreover, the fact that each species belongs to a different functional group with a significantly different activity rate (i.e. different metabolic requirements) and each one selected a different non-prey food according to the best results in terms of longevity provides a crossvalidation of our interpretation. Predictions in this sense should be made carefully because it is still not clear if this pattern is consistent within and across functional groups since we tested only one species per guild. In addition, variations in the nutritional quality of non-prey foods (e.g. pollen and honey) may play a role on the lifespan of spiders, and the effect of the availability of alternative food for predators is not clear. For example, Harwood and Obrycki (2005) suggested that alternative prey might lead to a reduction in pest control provided by Erigone autumnalis (Emerton) (Araneae: Linyphiidae). On the other hand, habitat management practices such as maintaining weed strips in the crop may provide this valuable source of alternative non-prey foods helping to keep the communities of natural enemies healthy within the agroecosystem, which can contribute for biological pest control.

\section{Author contributions}

J.B.M., S.A.P.S., J.A.P. and J.P.S. conceived and designed the experiment, J.B.M collected the spiders, performed the laboratory experiments and analyzed the data, S.A.P.S. and J.A.P. provided assistance during the laboratory experiments, and all the authors contributed to writing the paper.

\section{Acknowledgements}

The authors are grateful to the Portuguese Foundation for Science and Technology for financial support through the project EXCL/AGR$\mathrm{PRO} / 0591 / 2012$ "Olive crop protection in sustainable production under global climatic changes: linking ecological infrastructures to ecosystem functions" and Centro 2020 through the project Centro-010145-FEDER-000007 "ReNATURE - Valorization of the Natural Endogenous Resources of the Centro Region". Jacinto Benhadi-Marín thanks FCT for the Ph.D. grant SFRH/BD/97248/2013. This manuscript is part of Jacinto Benhadi-Marín's Ph.D. thesis. The authors declare that they have no conflict of interest.

\section{References}

Ajuria, H., Reader, T., 2014. Female-limited colour polymorphism in the crab spider Synema globosum (Araneae: Thomisidae). Biol. J. Linnean Soc. 113 (2), 368-383. 
Benhadi-Marín, J., Pereira, J.A., Bento, A., Sousa, J.P., Santos, S.A.P., 2016. Biodiversity of spiders in agroecosystems: community structure, conservation and roles as biological control agents. In: Santos, S.A.P. (Ed.), Natural Enemies: Identification, Protection Strategies and Ecological Impacts. Nova Science Publishers, Hauppauge New York pp. 218.

Bilde, T., Toft, S., 2001. The value of three cereal aphid species as food for a generalist predator. Physiol. Entomol. 26, 58-68.

Chen, X., Chen, Y., Wu, L., Peng, Y., Chen, J., Liu, F., 2010. A survey of nectar feeding by spiders in three different habitats. Bull. Insectol. 63, 203-208.

Creager, M.S., Izdebski, T., Brooks, A.E., Lewis, R.V., 2011. Elucidating metabolic pathways for amino acid incorporation into dragline spider silk using $13 \mathrm{C}$ enrichment and solid state NMR. Comp. Biochem. Physiol. A. Mol. Integr. Physiol. 159 (3), 219-224.

Dinis, A.M., Pereira, J.A., Benhadi-Marín, J., Santos, S.A.P., 2016. Feeding preferences and functional responses of Calathus granatensis and Pterostichus globosus (Coleoptera: Carabidae) on pupae of Bactrocera oleae (Diptera: Tephritidae). Bull. Entomol. Res. 106 (6), 701-709.

Drewes, C.D., Bernard, R.A., 1976. Electrophysiological responses of chemosensitive sensilla in the wolf spider. J. Exp. Zool. 198, 423-1328.

Fischer, M.K., Völkl, W., Hoffmann, K.H., 2005. Honeydew production and honeydew sugar composition of polyphagous black bean aphid, Aphis fabae

(Hemiptera:Aphididae) on various host plants and implications for ant-attendance. Eur. J. Entomol. 102, 155-160.

Foelix, R., 1996. How do crab spiders (Thomisidae) bite their prey? Rev. suisse zool. vol. hors série 203-210.

Foelix, R., 2011. Biology of Spiders. Oxford University Press, New York, USA pp. 432.

Harwood, J.D., Obrycki, J.J., 2005. The role of alternative prey in sustaining predator populations. Second International Symposium on Biological Control of Arthropods, Davos, Switzerland. pp. 453-462.

Heiling, A.M., Cheng, K., Herberstein, M.E., 2004. Exploitation of floral signals by crab spiders (Thomisus spectabilis, Thomisidae). Behav. Ecol. 15, 321-326.

Hermosín, I., Chicón, R.M., Cabezudo, M.D., 2003. Free amino acid composition and botanical origin of honey. Food Chem. 83, 263-268.

Kaushik, J.K., Bhat, R., 2003. Why is trehalose an exceptional protein stabilizer? J. Biol. Chem. 278 (29), 26458-26465.

Kuhn-Nentwig, L., Stöcklin, R., Nentwig, W., 2011. Venom composition and strategies in spiders: Is everything possible? Adv. In Insect. Phys. 40, 1-86.

Kurtzmann Jr., R.H., 1997. Nutrition from mushrooms, understanding and reconciling available data. Mycoscience 38, 247-253.

Ludy, C., Lang, A., 2006. Bt maize pollen exposure and impact on the garden spider, Araneus diadematus. Entomol. Exp. Appl. 118, 145-156.

Lundgren, J.G., 2009. Relationships of Natural Enemies and Non-prey Foods. Springer International, Dordrecht, Netherlands, pp. 454.

Morano, E., Carrillo, J., Cardoso, P., 2014. Iberian spider catalogue. (v3.1). http://www. ennor.org/iberia (accessed 23.07.18)

Nentwig, W., Blick, T., Gloor, D., Hänggi, A., Kropf, C., 2018. Spiders of Europe. (v04. 2018). www.araneae.unibe.ch. (accessed 23.07.18.).

Nentwig, W., 1987. Ecophysiology of Spiders. Nentwig, W. (Ed). Springer-Verlag, Berlin, Heidelberg. pp. 448.

Noldus Media Recorder, 2013b. http://www.noldus.com/human-behavior-research/ products/media-recorder-0. (accessed 23.07.18.).

Noldus Observer XT., 2013a. http://www.noldus.com/human-behavior-research/products/the-observer-xt. (accessed 23.07.18.)

Noldus, L.P.J.J., 1991. The observer: a software system for collection and analysis of observational data. Behav. Res. Methods Instrum. Comput. 23, 415.

Nyffeler, M., Olson, E.J., Symondson, W.O.C., 2016. Plant-eating by spiders. J. Arachno. $44,15-27$

Pasupuleti, V.R., Sammugam, L., Ramesh, N., Gan, S.H., 2017. Honey, propolis, and royal jelly: a comprehensive review of their biological actions and health benefits. Oxid. Med. Cell. Longev. 1259510, 21 pp.

Patt, J.M., Pfannenstiel, R.S., 2008. Odour-based recognition of nectar in spiders.
Entomol. Exp. Appl. 127, 64-71.

Patt, J.M., Pfannenstiel, R.S., 2009. Characterization of restricted area searching behavio following consumption of prey and non-prey food in a cursorial spider, Hibana futilis. Entomol. Exp. Appl. 132, 13-20.

Pfannenstiel, R.S., 2015. Extended survival of spiders (Aranaeae) feeding on whitefly (Homoptera: Aleyrodidae) honeydew. J. Entomol. Sci. 50 (2), 110-118.

Pfannenstiel, R.S., Patt, J.M., 2012. Feeding on nectar and honeydew sugars improves survivorship of two nocturnal cursorial spiders. Biol. Control 63, 231-236.

Picchi, M.S., Marchi, S., Albertini, A., Petacchi, R., 2017. Organic management of olive orchards increases the predation rate of overwintering pupae of Bactrocera oleae (Diptera: Tephritidae). Biol. Control 108, 9-15.

Pollard, S.D., 1990. The feeding strategy of a crab spider, Diaea sp. indet (Araneae, Thomisidae): post-capture decision rules. J. Zool. 222, 601-615.

Pollard, S.D., Beck, M.W., Dodson, G.N., 1995. Why do male crab spiders drink nectar? Animal Behav. 49, 1443-1448.

R Core Team, 2018. R: a Language and Environment for Statistical Computing. R Foundation for Statistical Computing, Vienna, Austria. http://www.R-project.org (accessed 23.7.18.)

Ruhren, S., Handel, S.N., 1999. Jumping spiders (Salticidae) enhance the seed production of a plant with extrafloral nectaries. Oecologia 116, 227-230.

Sanders, D., 2012. Herbivory in spiders. In: Nentwig, W. (Ed.), Spider Ecophysiology. Springer, Berlin, Heidelberg.

Suetsugu, K., Hayamizu, M., Koike, N., 2014. Clubiona spider (Araneae: Clubionidae) visiting flowers of nectariferous orchid Neottianthe cucullata. Entomol. Sci. 17, 262-264.

Taylor, R., Pfannenstiel, R.S., 2009. How dietary plant nectar affects the survival, growth, and fecundity of a cursorial spider Cheiracanthium inclusum (Araneae: Miturgidae). Environ. Entomol. 38 (5), 1379-1386.

Vallet, A.M., Marion-Poll, F., Trabalon, M., 1998. Preliminary electrophysiological study of the contact chemoreceptors in a spider. Comptes Rendus Acad. Sci. Series III - Sci. de la Vie 321 (6), 463-469.

van Rijn, P.C.J., van Houten, Y.M., Sabelis, M.W., 2002. How plants benefit from pro viding food to predators even when it is also edible to herbivores. Ecology 83, 2664-2679.

Villa, M., Santos, S.A.P., Benhadi-Marín, J., Mexia, A., Bento, A., Pereira, J.A., 2016. Lifehistory parameters of Chrysoperla carnea s.l. fed on spontaneous plant species and insect honeydews: importance for conservation biological control. BioControl 61 (5), 533-543.

Vogelei, A., Greissl, R., 1989. Survival strategies of the crab spider Thomisus onustus Walckenaer, 1806 (Chelicerata, Arachnida, Thomisidae). Oecologia 80, 513-515.

Vollhardt, I.M.G., Bianchi, F.J.J.A., Wäckers, F.L., Thies, C., Tscharntke, T., 2010. Spatial distribution of flower vs. honeydew resources in cereal fields may affect aphid parasitism. Biol. Control 53 (2), 204-213.

Wäckers, F.L., van Rijn, P.C.J., Heimpel, G.E., 2008. Honeydew as a food source for natural enemies: making the best of a bad meal? Biol. Control 45, 176-184.

Walter, A., Bechsgaard, J., Scavenius, C., Dyrlund, T.S., Sanggaard, K.W., Enghild, J.J., Bilde, T., 2017. Characterisation of protein families in spider digestive fluids and their role in extra-oral digestion. B.M.C Genomics 18 (1), 13.

Watanabe, M., 2006. Anhydrobiosis in invertebrates. Appl. Entomol. Zool. 41 (1), 15-31.

Wilder, S.M., 2011. Spider nutrition: an integrative perspective. Adv. In Insect. Phys. 40 87-136.

Wu, L., Yun, Y., Li, J., Chen, J., Zhang, H., Peng, Y., 2011. Preference for feeding on honey solution and its effect on survival, development, and fecundity of Ebrechtella tricuspidata. Entomol. Exp. Appl. 140, 52-58.

Zax, D.B., Armanios, D.E., Horak, S., Malowniak, C., Yang, Z., 2004. Variation of mechanical properties with amino acid content in the silk of Nephila clavipes. Biomacromolecules 5, 732-738.

Zuur, A., Ieno, E.N., Walker, N., Saveliev, A.A., Smith, G.M., 2009. Mixed Effects Models and Extensions in Ecology with R. Springer, New York, pp. 574. 